OPEN ACCESS

Edited by:

Philipp Albrecht,

Heinrich Heine University of

Düsseldorf, Germany

Reviewed by:

Nico Melzer,

University Hospital of

Düsseldorf, Germany

Anne Eugster,

Technische Universität

Dresden, Germany

${ }^{*}$ Correspondence:

Geoffrey C. Owens

geoffreyowens@mednet.ucla.edu

Specialty section:

This article was submitted to

Multiple Sclerosis and

Neuroimmunology,

a section of the journal

Frontiers in Immunology

Received: 05 February 2021

Accepted: 16 March 2021

Published: 06 April 2021

Citation:

Chang JW, Reyes SD, Faure-Kumar E,

Lam SK, Lawlor MW, Leventer RJ,

Lew SM, Lockhart PJ, Pope K,

Weiner HL, Salamon N, Vinters HV,

Mathern GW, Fallah A and Owens GC (2021) Clonally Focused Public and

Private T Cells in Resected Brain

Tissue From Surgeries to Treat

Children With Intractable Seizures.

Front. Immunol. 12:664344.

doi: 10.3389/fimmu.2021.664344

\section{Clonally Focused Public and Private T Cells in Resected Brain Tissue From Surgeries to Treat Children With Intractable Seizures}

\author{
Julia W. Chang ${ }^{1}$, Samuel D. Reyes ${ }^{1}$, Emmanuelle Faure-Kumar ${ }^{2}$, Sandi K. Lam ${ }^{3}$, \\ Michael W. Lawlor ${ }^{4}$, Richard J. Leventer ${ }^{5}$, Sean M. Lew ${ }^{6}$, Paul J. Lockhart ${ }^{5}$, \\ Kathryn Pope ${ }^{5}$, Howard L. Weiner ${ }^{7}$, Noriko Salamon ${ }^{8}$, Harry V. Vinters ${ }^{9}$, \\ Gary W. Mathern ${ }^{1}$, Aria Fallah ${ }^{1,10}$ and Geoffrey C. Owens ${ }^{1 *}$
}

${ }^{1}$ Department of Neurosurgery, David Geffen School of Medicine at the University of California, Los Angeles, CA, United States, ${ }^{2}$ Department of Medicine: Division of Digestive Diseases, David Geffen School of Medicine at the University of California, Los Angeles, CA, United States, ${ }^{3}$ Department of Neurological Surgery, Feinberg School of Medicine, Northwestern University, Ann \& Robert H. Lurie Children's Hospital, Chicago, IL, United States, ${ }^{4}$ Department of Pathology, Medical College of Wisconsin, Children's Hospital of Wisconsin, Milwaukee, WI, United States, ${ }^{5}$ Murdoch Children's Research Institute, Royal Children's Hospital, Parkville, VIC, Australia, ${ }^{6}$ Department of Neurosurgery, Medical College of Wisconsin, Children's Hospital of Wisconsin, Milwaukee, WI, United States, ${ }^{7}$ Department of Pediatric Neurosurgery, Baylor College of Medicine, Texas Children's Hospital, Houston, TX, United States, ${ }^{8}$ Department of Radiological Sciences, David Geffen School of Medicine at the University of California, Los Angeles, CA, United States, ${ }^{9}$ Department of Pathology and Laboratory Medicine, David Geffen School of Medicine at the University of California, Los Angeles, CA, United States,

10 Mattel Children's Hospital, David Geffen School of Medicine at the University of California, Los Angeles, CA, United States

Using a targeted transcriptomics approach, we have analyzed resected brain tissue from a cohort of 53 pediatric epilepsy surgery cases, and have found that there is a spectrum of involvement of both the innate and adaptive immune systems as evidenced by the differential expression of immune-specific genes in the affected brain tissue. The specimens with the highest expression of immune-specific genes were from two Rasmussen encephalitis cases, which is known to be a neuro-immunological disease, but also from tuberous sclerosis complex (TSC), focal cortical dysplasia, and hemimegalencephaly surgery cases. We obtained $T$ cell receptor (TCR) V $\beta$ chain sequence data from brain tissue and blood from patients with the highest levels of $T$ cell transcripts. The clonality indices and the frequency of the top $50 \mathrm{~V} \beta$ clonotypes indicated that $T$ cells in the brain were clonally restricted. The top $50 \mathrm{~V} \beta$ clonotypes comprised both public and private (patient specific) clonotypes, and the TCR V $\beta$ chain third complementarity region (CDR3) of the most abundant public $\mathrm{V} \beta$ clonotype in each brain sample was strikingly similar to a CDR3 that recognizes an immunodominant epitope in either human cytomegalovirus or Epstein Barr virus, or influenza virus A. We found that the frequency of 14 of the top 50 brain V $\beta$ clonotypes from a TSC surgery case had significantly increased in brain tissue removed to control recurrent seizures 11 months after the first surgery. Conversely, we found that the frequency in the blood of 18 of the top 50 brain clonotypes from a second TSC patient, who was seizure free, had significantly decreased 5 months after surgery indicating that $T$ cell clones found in the brain had 
contracted in the periphery after removal of the brain area associated with seizure activity and inflammation. However, the frequency of a public and a private clonotype significantly increased in the brain after seizures recurred and the patient underwent a second surgery. Combined single cell gene expression and TCR sequencing of brain-infiltrating leukocytes from the second surgery showed that the two clones were CD8 effector T cells, indicating that they are likely to be pathologically relevant.

Keywords: T cell receptor, epilepsy, Rasmussen encephalitis, focal cortical dysplasia, tuberous sclerosis complex

\section{INTRODUCTION}

Involvement of the humoral and cellular effector arms of the adaptive immune system in seizures associated with infection and autoimmunity is well established (1-4). Less well studied is a potential role of the adaptive immune system in cases of drug resistant epilepsy in which a direct link to an infectious agent or underlying autoimmune disease has not been established. In the pediatric population many of the operable cases of intractable epilepsy are associated with developmental abnormalities in the cerebral cortex, which result from mutations that dysregulate the growth and differentiation of neuronal precursors causing focal cortical dysplasia (FCD), hemimegalencephaly (HME), and tuberous sclerosis complex (TSC) $(5,6)$. Aronica and colleagues first documented the presence of $\mathrm{T}$ cells in pathological specimens from FCD, and TSC surgery cases $(7,8)$. Higher numbers of CD8 $\mathrm{T}$ cells were reported in sections from FCD type II brain tissue compared with FCD I brain specimens; T cells were observed in close proximity to dysmorphic neurons and balloon cells (8), a distinguishing pathological feature of FCD type II compared with FCD type I (9). Likewise, CD8 T cells were found in TSC tubers surrounding dysplastic neurons and balloon cells (7). More recently $\mathrm{Xu}$ et al. reported that immune cells isolated from resected brain tissue from pediatric epilepsy surgeries comprised antigen experienced CD4, CD8 and Th17 $\gamma \delta$ T cells (10). In agreement with these observations, we also found that effector memory $\mathrm{T}$ cells are present in brain tissue that has been removed to treat seizures associated with cortical malformations including FCD, TSC and HME (11). By mass cytometry approximately half of the CD8 $\alpha \beta$ T cells that we isolated from FCD $(n=4)$, TSC $(n=2)$ and HME $(n=1)$ surgery cases expressed CD69 (11), an activation marker (12). In the TSC and FCD cases, the $\alpha \beta \mathrm{T}$ cells isolated from the resected brain tissue comprised only a fraction of the brain-infiltrating leukocytes (BILs) ranging from $3.2 \%$ to $15.1 \%$; the remaining cells were either $\gamma \delta \mathrm{T}$ cells, natural killer (NK) or myeloid cells (11). By contrast, almost half of the $\mathrm{CD} 45^{+}$immune cells isolated from the HME brain tissue comprised CD69 ${ }^{+} \mathrm{CD} 4 \alpha \beta$ T cells $(25.6 \%)$ and CD69 ${ }^{+} \mathrm{CD} 8 \alpha \beta \mathrm{T}$ cells $(21.3 \%)$, suggesting an antigen driven T cell trafficking to the brain in this HME patient.

To investigate whether $\mathrm{T}$ cells in resected epileptogenic areas of the brain result from an adaptive immune response, we analyzed the $\mathrm{T}$ cell repertoires of a group of pediatric epilepsy surgery cases. Clonal restriction of $\mathrm{T}$ cells in the brain would be indicative of an antigen(s) driven immune response. We initially screened resected brain tissue from 53 pediatric epilepsy surgery cases for the expression of immune gene transcripts including five of the cases discussed above. We then sequenced $\mathrm{T}$ cell receptor (TCR) V $\beta$ chains in brain tissue and blood from cases with the highest levels of $\mathrm{T}$ cell transcripts. We found that the $\mathrm{T}$ cell repertoires in the brains of these cases were skewed towards a limited number of private (patient specific) and public clones. Further, the third complementarity regions (CDR3) of many of the abundant public TCR sequences were strikingly similar to those that recognize immunodominant epitopes in human cytomegalovirus (HCMV), or Epstein Barr virus (EBV), or influenza virus $\mathrm{A}$.

\section{MATERIALS AND METHODS}

\section{Patient Cohort}

This study was approved by the UCLA Institutional Review Board (IRB no. 18-001048). All of the patients or their parents or legal guardians provided informed consent for the use of the surgical remnant and blood for research purposes according to the Declaration of Helsinki. There were no exclusion criteria, and no reported comorbidities. All specimens were collected using the same standard operating procedures. De-identified patient information including age at seizure onset, age at surgery, and gender was collected with informed consent.

\section{RNA Transcript Analysis}

Bulk RNA was directly extracted from snap frozen blocks of involved brain tissue comprising grey and white matter from 53 pediatric epilepsy surgery cases (Direct-zol RNA miniprep kit; Zymo Research, Irvine, CA). A NanoString ${ }^{\circledR}$ immune cell profiling oligonucleotide array (nCounter ${ }^{\circledR}$ human immunology panel v2) was used to quantify transcripts expressed by $\mathrm{T}$ cells, macrophages and microglia (NanoString Technologies Inc, Seattle, WA). Data from five plates were combined and normalized and batch-corrected using the nSolver ${ }^{\mathrm{TM}} 4.0$ analysis software according to the manufacturer's protocol (NanoString Technologies Inc). For batch correction, RNA from the same surgery case was included in all five plates. The expression values were $\log 2$ transformed (Table S3), and subjected to principal components analysis (PCA) followed by hierarchical clustering of principal components using the $\mathrm{R}$ package FactoMinerR (13). 


\section{T Cell Receptor Sequencing}

Bulk genomic DNA was isolated from frozen blocks of fresh involved brain tissue from 13 of the 53 pediatric epilepsy surgery cases and whole blood from nine of these cases (Monarch ${ }^{\circledR}$ genomic DNA purification kit, New England Biolabs, Ipswich, MA). V $\beta$ chain TCR sequences were obtained using the ImmunoSEQ $^{\circledR}$ assay (Adaptive Biotechnologies, Seattle, WA). CDR3 sequences were manually curated to remove those that did not start with the third framework cysteine residue at position 104 (14). Clonality was calculated as described (15); comparison of proportions Chi-squared tests (16) were used to determine whether the frequency of the same V $\beta$ CDR3 sequence was significantly different between brain and blood samples from the same patient. Whether $\mathrm{V} \beta \mathrm{CDR} 3$ sequences corresponded to public $\mathrm{T}$ cell clones was determined by searching the immuneACCESS $^{\circledR}$ database (Adaptive Biotechnologies) and similarity to know anti-viral $\mathrm{T}$ cell clonotypes was determined using the VDJdb browser (17). Venn diagrams and heat maps were made with online tools (bioinformatics.psb.ugent.be/ webtools/Venn, software.broadinstitute.org/morpheus/). Venn diagrams and heat maps were exported to CorelDraw2017 as scalable vector graphics and portable document format files respectively (Corel Corporation, Ottawa, Canada).

\section{Mass Cytometry}

Peripheral blood mononuclear cells (PBMCs) were isolated from blood collected from Patients 595 and 597 at the time of surgery and from Patient 595 five months after surgery by density gradient centrifugation using Ficoll-Paque PLUS (GE Healthcare, Piscataway, NJ). Brain-infiltrating leukocytes (BILs) were isolated from a block of fresh involved 597 brain tissue by overnight digestion with Type IV collagenase (Worthington Biochemical Corp. Lakewood, NJ) followed by fractionation on a 70\%:30\% Percoll $^{\circledR}$ (Millipore Sigma, St. Louis MO) step gradient (18). All metal-tagged antibodies (Abs) were obtained from the Fluidigm Corporation (San Francisco, CA), and PBMCs and BILs were stained according to Fluidigm's protocol as previously described (11). The antibody (Ab) panel comprised the following markers: CD45 (89Y or 115In), CD196 (141Pr), CD19 (142Nd), CD127 (143Nd), CD69 (144Nd), CD4 (145Nd), CD8a (146Nd), CD11c (147Sm), CD25 (149Sm), CD103 (151Eu), TCR $\gamma \delta$ (152Sm), CD192 (153Eu), CD45RO (154Sm), CD279 (155Gd), CD183 (156Gd), CD33 (158Gd), CD197 (159Tb), CD14 (160Gd), CD152 (161Dy), CD27 (162Dy), CD56 (163Dy), CD38 (164Dy), CD16 (165Ho), CD28 (166Er), CD11b (167Er), CD206 (168Er), CD45RA (169Tm), CD3 (170Er), CD195 (171Yb), HLA-DR (174Yb), CD194 (175Lu), CD57 (176Yb). The Ab cocktail for staining PBMCs isolated from Patient 595 at the time of surgery (presurgery PBMCs) contained the CD45 Ab conjugated to Indium115 (115In) while the Ab cocktail for staining PBMCs from blood collected at a follow-up appointment after surgery (post-surgery PBMCs) contained the CD45 Ab tagged with Yttrium 89 (89Y). Likewise, the PBMCs and BILs from Patient 597 were stained with Ab cocktails containing CD45 Abs conjugated to $115 \mathrm{In}$ and $89 \mathrm{Y}$ respectively. To minimize technical variability, the 595 pre- and post- PBMCs were stained at the same time, then combined as a single sample and run on a Helios ${ }^{\circledR}$ cytometry by time of flight (CyTOF) system (Fluidigm Corporation). The 597 BILs and PBMCs were also stained in parallel and then combined. Post-acquisition data normalization was done using bead-based normalization in the CyTOF software. Data were analyzed using Cytobank (19). Prior to analysis, events were gated to eliminate normalization beads, debris, dead cells and doublets. The 595 pre- and post- surgery PBMC data were then split into two separate FCS files by gating on the two different CD45 metal conjugated Abs. Likewise the 597 PBMC and BIL data were separated into two FCS files. To define subsets of immune cells the high dimensional data from 10,000 randomly selected cells from each sample were converted into a matrix of pair-wise similarities by implementing the $t$ based stochastic neighbor embedding ( $t$-SNE) algorithm, followed by a density-based clustering method (ClusterX) (20).

\section{Immunocytochemistry}

Adjacent sections $(5 \mu \mathrm{m})$ of involved tissue were immunostained as previously described (21). Sections were stained with a CD3 mouse monoclonal Ab (clone F7.2.38, 1:500; Agilent Technologies Inc., Santa Clara, CA) and an Ibal rabbit polyclonal Ab (1:500; Fujifilm Wako Chemicals Corp. Richmond, VA). Staining was visualized by adding 3, 3'diaminobenzidine (Sigma-Aldrich, St. Louis, MO), followed by counterstaining with hematoxylin. Images were acquired using an Aperio ScanScope XT scanner (Aperio, Vista CA), then transferred to CorelPhoto-Paint, and rescaled from $72 \mathrm{dpi}$ to 600 dpi. Images were then transferred to CorelDRAW2017; no changes were made to contrast or color balance.

\section{Single Cell RNAseq}

BILs were isolated as described above from a block of fresh resected brain tissue from Patient 595. Two Chromium single cell gene expression libraries (5' gene expression and TCR V (D)J) were prepared from the same cells (10X Genomics, Pleasanton, CA). Sequencing was performed on a NextSeq500 SBS sequencing v2 2x75 (Illumina Inc., San Diego, CA). Data were demultiplexed and aligned to GRCh38 transcriptome and VDJ references using Cell Ranger count and Cell Ranger VDJ pipelines (10X Genomics). Gene expression and TCR sequences in single cells were visualized with Loupe Browser and Loupe VDJ Browser respectively (10X Genomics). Single cell heat maps were exported to CorelDraw2017 as scalable vector graphics files.

\section{RESULTS}

\section{A Spectrum of Expression of Immune Genes in Resected Epileptogenic Brain Tissue}

We used a NanoString ${ }^{\circledR}$ immune cell profiling oligonucleotide array to measure the expression of immune genes in resected brain tissue from 53 pediatric patients presenting with 
intractable epilepsy who underwent surgery to control their seizures. Based on available clinical reports patients had been treated with at least one anti-epileptic drug; two of the RE patients (case IDs 484 and 573) had received intravenous injections of immunoglobulins. Patient 573 had also been treated with the corticosteroid prednisolone, as had TSC patient 595. From clinical and pathological evaluation, seizures were associated with TSC $(n=20), \operatorname{FCD}(n=20), \operatorname{RE}(n=5)$, perinatal arterial ischemic stroke (PAIS) $(n=5)$, and HME $(n=3)$ (Table S1). PCA of the normalized batch expression of 577 genes (Table S3) followed by hierarchical clustering resolved the study cohort into three groups (Figures 1A, B). We selected 175 genes that defined Cluster 3 whose expression levels were significantly different from the other two clusters $(\mathrm{p}<0.0001)$, and assigned these genes to $\mathrm{T}$ cells, microglia and macrophages based on published single cell RNA sequencing data (Figures 1C, D)
A

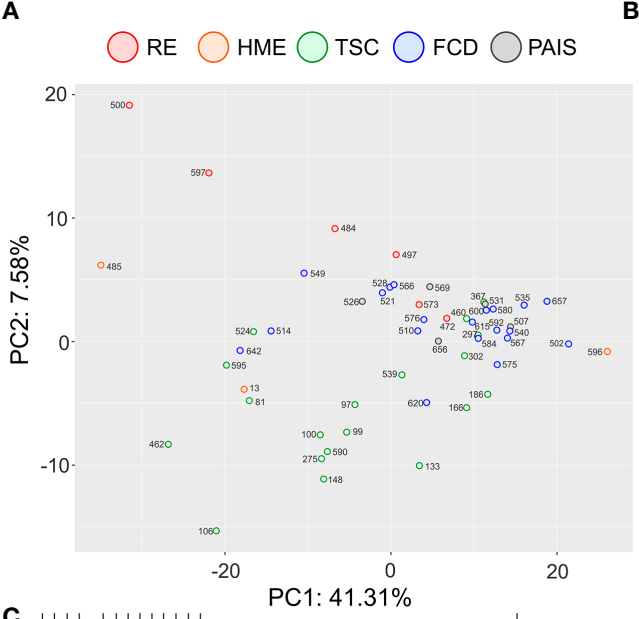

C

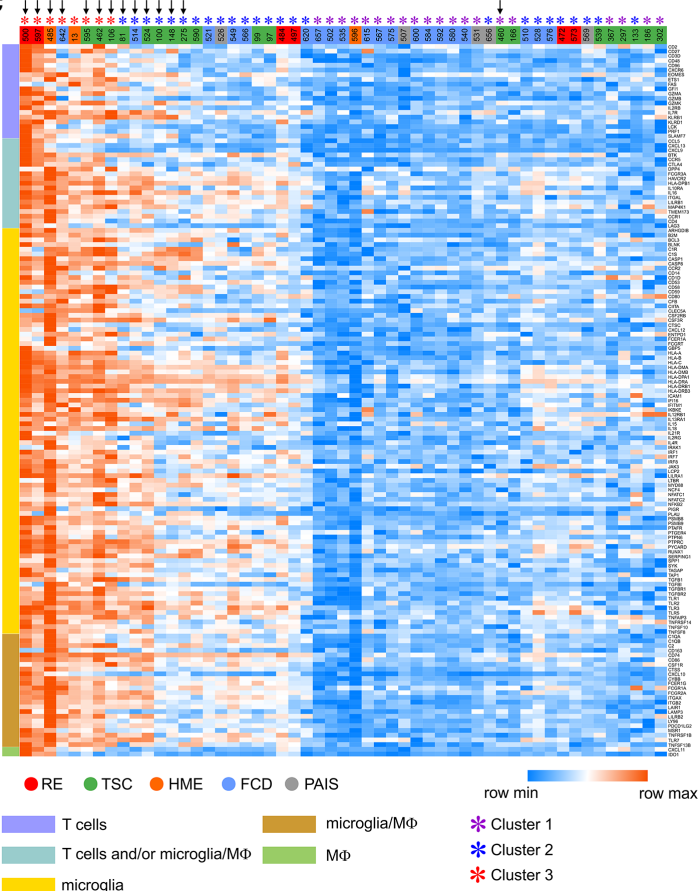

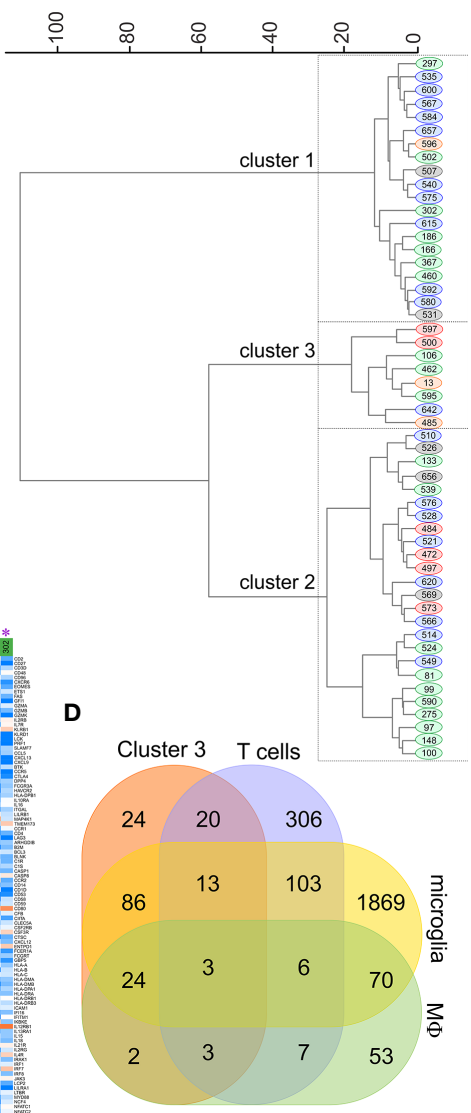

E

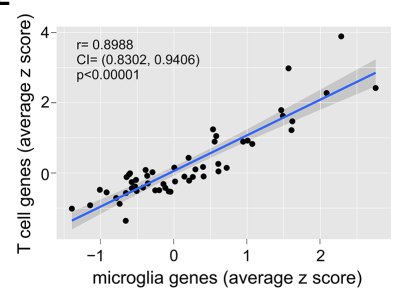

FIGURE 1 | Quantification of immune cells transcripts in resected brain tissue from epilepsy surgeries. A NanoString ${ }^{\circledR}$ immune cell profiling oligonucleotide array was used to quantify transcripts expressed by T cells, macrophages and microglia in brain specimens from 53 pediatric epilepsy surgery cases. (A) PCA plot calculated from the batch corrected normalized data. (B) Hierarchical clustering (Ward's method) of the PCA coordinates resulted in three clusters. (C) Heat map after hierarchical clustering (Euclidean distances) showing the modified z scores (based on the median) of 86 percent of the genes whose expression was significantly higher $(p<0.0001)$ in Cluster 3 and could be assigned to T cells, microglia or macrophages $(M \Phi)$. Vertical down arrows mark the cases from which TCR V $\beta$ sequences were obtained. (D) Venn diagram showing the assignment of 151 out of 175 genes whose expression was significantly higher $(p<0.0001)$ in Cluster 3 to $T$ cells, microglia or macrophages. (E) Plot showing a positive linear correlation between the expression of $\mathrm{T}$ cell specific genes and microglia specific genes in brain tissue from 53 epilepsy surgeries. 
(22-25). Unsupervised re-clustering of the patient samples based on Euclidean distances calculated from the $\mathrm{z}$ scores of the 151 cell-assigned genes showed that the Cluster 3 brain specimens expressed the highest levels of $\mathrm{T}$ cell and microglia/macrophage transcripts. Specimens in Cluster 1 expressed the lowest levels of these immune cell transcripts, whereas the cases that comprised Cluster 2 split into two groups after re-clustering, a high/ intermediate group and cases interspersed with those comprising Cluster 1 (Figures 1B, C). We found a highly significant correlation between the transcript levels of microglia specific and $\mathrm{T}$ cell specific genes likely reflecting the presence of higher numbers of both infiltrating $\mathrm{T}$ cells and microglia (Figure 1E). The brain tissue specimens with the highest expression of immune-specific genes were from two of the RE cases, which is known to be a neuro-immunological disease with a defining inflammatory component (26-28), but also from TSC, FCD, and HME surgery cases. Immunostaining adjacent sections of resected brain tissue from three TSC cases with a high immune gene expression signature showed $\mathrm{CD}^{+} \mathrm{T}$ cells and $\mathrm{Iba}^{+}$microglia in close proximity to dysmorphic cells (Figure S1). There was no significant correlation between the $\mathrm{T}$ cell gene expression signature and the patient's age at the time of surgery or the time from seizure onset to surgery irrespective of gender (Figure S2).

\section{Clonally Focused T Cells Are Found in Resected Epileptogenic Brain Tissue}

We isolated genomic DNA for V $\beta$ chain TCR sequencing from 12 surgery cases with the highest $\mathrm{T}$ cell signatures based on the NanoString ${ }^{\circledR}$ data. For eight of the cases, we also extracted genomic DNA from a sample of blood that was drawn just prior to the surgery. In addition, we extracted genomic DNA from brain and blood specimens from surgery case 460 because the same patient underwent a second surgery 11 months later (surgery case 524) (Table S1). As shown in Figure 1C, relatively fewer immune cell transcripts were found in brain tissue from the first surgery compared with the second surgery (460 versus 524).

To assess how clonally restricted $\mathrm{T}$ cells were from the brain and the blood we calculated a clonality index, which is defined as one minus the normalized Shannon's Diversity Index, and varies from 0 , maximal diversity, to 1 in a completely oligoclonal sample, and can account for differences in sequencing depth between samples (15). As shown in Table 1 the clonality indices in the brain varied, however they were significantly different overall compared with the blood $(p=0.01$, Wilcoxon SignedRank for small samples). This implies that there must be some selective enrichment of $\mathrm{T}$ cell clones in the affected brain area of these patients. The clonality index for case 275 was very low suggesting that $\mathrm{T}$ cells in the affected area of the brain of this patient were not clonally restricted. Not unexpectedly the two RE cases (500 and 597) with the highest $\mathrm{T}$ cell gene expression signature (Figure 1) had the highest clonality scores in the brain (Table 1). The clonality score for T cells in blood from Patient 597, was also strikingly high, which is likely attributable to three public V $\beta$ clonotypes that comprised $20.3 \%$ of the sample of the
TABLE 1 | Clonality indices.

\begin{tabular}{lcc}
\hline Case ID & Brain & Blood \\
\hline 514 & 0.0100 & 0.0043 \\
642 & 0.1057 & 0.0465 \\
485 & 0.0638 & 0.0414 \\
500 & 0.3702 & 0.0094 \\
597 & 0.4281 & 0.2385 \\
81 & 0.0742 & n.a. \\
100 & 0.2546 & n.a. \\
106 & 0.1480 & n.a. \\
275 & 0.0087 & n.a. \\
460 & 0.0340 & 0.04154 \\
462 & 0.2173 & 0.0575 \\
524 & 0.0811 & 0.0442 \\
595 & 0.1084 & 0.0183
\end{tabular}

$H=-\Sigma P_{i} \cdot \log _{2} P_{i}\left(P_{i}=\right.$ freq. of a unique CDR3 amino acid sequence).

$H_{\text {max }}=\log _{2} N$ ( $N=$ total no. of unique CDR3 amino acid sequences).

$H_{\text {norm }}=H / H_{\text {max }}$.

Clonality index $=1-H_{\text {norm }}$.

n.a, not available.

repertoire (Figures 2A, B). We surveyed the composition of PBMCs isolated from the same sample of blood and identified two populations of antigen experienced CD8 $\mathrm{T}$ cells that comprised $\sim 50$ percent of the $\mathrm{T}$ cells in the PBMCs, suggesting that the three dominant public clones may correspond to these $\mathrm{T}$ cells (Figure 2C). The same transitional memory $\mathrm{T}$ cells were also found in the brain of Patient 597 (Figure 2C). We ascribed a transitional effector to memory phenotype to these $\mathrm{T}$ cells, because they co-expressed CD45RO and CD45RA as well as HLA-DR, CCR5, PD1, CD28 and CD11b (Figure S3).

\section{Public and Private TCR V $\beta$ Clonotypes Are Found in Resected Epileptogenic Brain Tissue}

The top $50 \mathrm{~V} \beta \mathrm{CDR} 3$ amino acid sequences in brain specimens from the 13 surgery cases accounted for 5-70 percent of the total number of V $\beta$ CDR3 sequences that were sampled (Figure 3). They were made up of both private and public $\mathrm{V} \beta$ clonotypes based on a search of the immuneACCESS ${ }^{\circledR}$ database (Figure 3). Comparison with TCR sequences in the iReceptor database (29) confirmed that the predominant private clones were patientspecific. In 11 out of the 13 surgery cases there was an even greater proportion of public than private $\mathrm{V} \beta$ clonotypes. In Table 2 we list the V $\beta$ CDR3 amino acid sequences from the most abundant public and private $\mathrm{T}$ cell V $\beta$ clonotypes in each brain specimen. For patients where the same clonotype is present in the blood, we found that it is significantly enriched in the brain; we used a comparison of proportions Chi-squared test in order to take into account the different sample sizes. Because of the high proportion of abundant public $\mathrm{V} \beta$ clonotypes in the brain tissue, we asked whether they may be similar to TCRs that recognize common infectious agents. By searching the VDJ database (17), we found that the V $\beta$ CDR3 amino acid sequence from the most abundant public V $\beta$ clonotype in each surgery case is very similar to a sequence known to recognize an immunodominant viral epitope (Table 2). In the case of Patient 106 we found an exact match to a V $\beta$ CDR3 sequence from a 

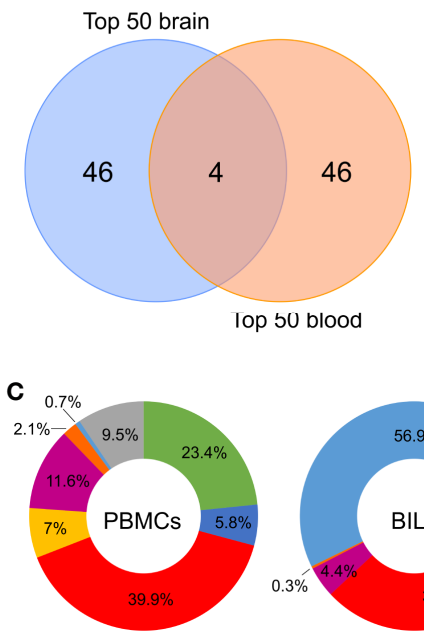

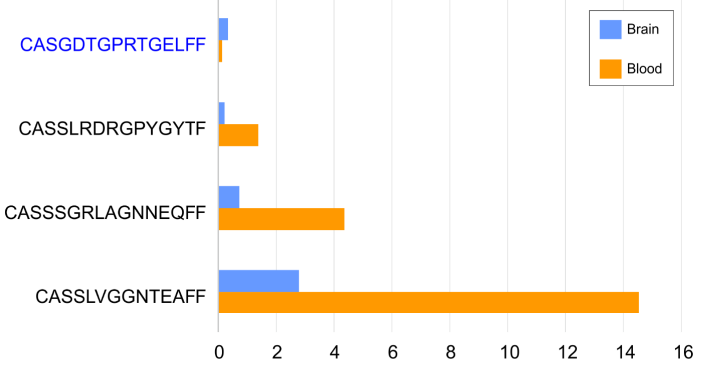

Percent of total no. of $\mathrm{V} \beta \mathrm{CDR} 3$ sequences

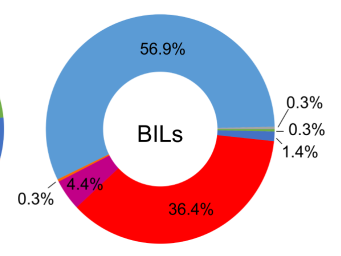

CD4 $\mathrm{T}_{\mathrm{N}}$ cells
CD4 $\mathrm{T}_{\mathrm{TM}}$ cells
CD8 $\mathrm{T}_{\mathrm{TM}}$ cells
CD8 $\mathrm{T}_{\mathrm{N}}$ cells

CD8 $\mathrm{T}_{\mathrm{TM}}$ cells $\left(\mathrm{CD}^{+} 7^{+}\right)$

CD8 $\mathrm{T}_{\mathrm{N}}$ cells $\left(\mathrm{CXCR3}^{+}\right)$

$\gamma \delta T_{T M}$ cells

$\gamma \delta \mathrm{T}_{\mathrm{N}}$ cells

FIGURE 2 | Overlap between abundant brain and blood T cell clonotypes in a Rasmussen encephalitis patient. (A) Venn diagram showing the overlap between the top 50 brain and top 50 blood T cell clonotypes in Patient 597. (B) Relative frequency of the four overlapping $T$ cell clonotypes in blood and brain. The private V $\beta$ CDR3 amino acid sequence is in blue, public V $\beta$ CDR3 sequences are in black. (C) Donut plots showing the relative frequency of $T$ cell subsets in $C D 45^{+}$CD $3^{+}$cells in peripheral mononuclear cells (PBMCs) and brain-infiltrating leukocytes (BILs). $T_{N}$, naïve $T$ cells; $T_{T M}$, transitional memory $T$ cells.

Public $v$ private clones in top 50 TCRs (\%) Top 50 TCRs $\begin{array}{lllllllllll}0 & 10 & 20 & 30 & 40 & 50 & 60 & 70 & 80 & 90 & 100\end{array}$ (\% total no.)

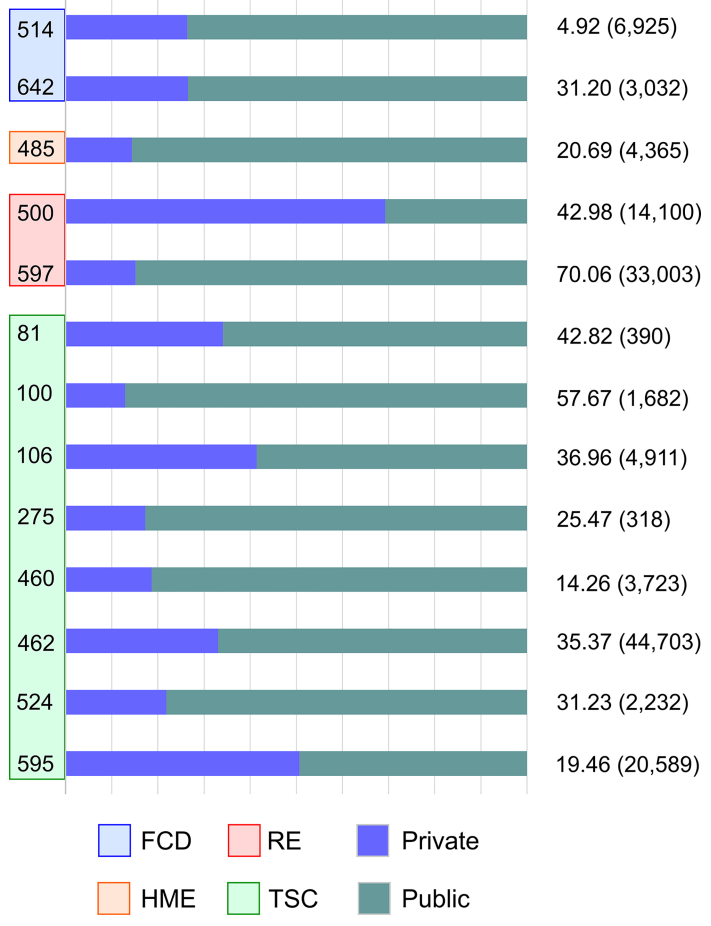

FIGURE 3 | The top 50 T cell clonotypes in brain comprise public and private clonotypes. Bar graphs showing the relative proportion of public and private clonotypes in the top $50 \mathrm{~T}$ cell clonotypes from each patient along with the percentage of the total sampled repertoire that each of the top 50 clonotypes represents. The total number of clonotypes identified is shown in parentheses.
$\mathrm{T}$ cell that recognizes an Epstein Barr virus antigen presented by HLA-A ${ }^{\star} 02$, although we do not know whether Patient 106 has the HLA-A ${ }^{\star} 02$ allele. However, we determined that TSC patient 595 has the HLA-A ${ }^{\star} 03$ allele (Table S2), which has been shown to present the HCMV peptide KLGGALQAK to a TCR with a V $\beta$ CDR3 sequence that differs by a single amino acid from the most abundant public V $\beta$ CDR3 in the brain of this patient (Table 2) (17). The closest match to the TCR V $\beta$ CDR3 sequence in the most abundant public V $\beta$ clonotype in the brain of Patient 597 is a V $\beta$ CDR3 sequence that recognizes the HCMV antigen KLGGALQAK restricted on HLA-A*03 (Table 2) (17). However, we found that this patient does not carry this allele (Table S2). There is a less stringent match to a V $\beta$ CDR3 sequence (CSSPTRNTEAFF) that binds the HCMV pp65 peptide, TPRVTGGGAM bound to HLA $\mathrm{B}^{\star} 07$, which Patient 597 does carry. The most abundant public V $\beta$ clonotype in the blood of this patient, which is also found among the top $50 \mathrm{~V} \beta$ clonotypes in the brain (Figure 2), may recognize another HCMV peptide bound by HLA $A^{\star} 01$, a class I allele the patient also carries (Table S2). The V $\beta$ CDR3 sequence, CASSLFGGNTEAFF, recognizes the pp50 peptide VTEHDTLLY and differs by a single amino acid from the V $\beta$ CDR3 sequence found in the blood of Patient 597 (CASSLVGGNTEAFF, Figure 2).

\section{Changes in the TCR Repertoire Between the First and Second Surgery}

As previously mentioned, surgery cases 460 and 524 correspond to the same TSC patient who was operated on twice within 11 months to remove epileptogenic tubers. The most abundant public and private TCR V $\beta$ clonotypes in the brain from the two surgeries are not the same (Table 2). We measured the 
TABLE 2 | Frequency of the top private and public V $\beta$ CDR3 sequences.

\begin{tabular}{|c|c|c|c|c|c|c|c|c|c|}
\hline $\begin{array}{l}\text { Case } \\
\text { ID }\end{array}$ & Pathology & CDR3 & $\begin{array}{l}\text { percent in } \\
\text { brain }\end{array}$ & $\begin{array}{l}\text { percent in } \\
\text { blood }\end{array}$ & $p$ value & $\begin{array}{c}\text { Similar virusspecific } \\
\text { CDR3 }\end{array}$ & Epitope & Antigen & Virus \\
\hline \multirow[t]{2}{*}{514} & FCD IIID & CASSLREGAQWVSPLHF & 0.245 & 0.054 & $p<0.0001$ & none & & & \\
\hline & & CASATALNYGYTF & 0.448 & 0.001 & $p<0.0001$ & CASASA-NYGYTF & NLVPMVATV & pp65 & HCMV \\
\hline \multirow[t]{2}{*}{642} & FCD IIIB & CASSQLGTSKFNEQFF & 3.496 & 0.285 & $p<0.0001$ & none & & & \\
\hline & & CASSSTVGGSTGELFF & 4.914 & 0.065 & $p<0.0001$ & CASSS-VASGGSTGELFF & KLGGALQAK & $\mathrm{IE} 1$ & HCMV \\
\hline \multirow[t]{2}{*}{485} & HME & CASRAGTGGGQQPQHF & 0.458 & 0.028 & $p<0.0001$ & none & & & \\
\hline & & CASSPGGFPLHF & 2.543 & 1.655 & $p<0.0001$ & CASSPGG-LHF & KLGGALQAK & IE1 & HCMV \\
\hline \multirow[t]{2}{*}{500} & RE & CASTHGHEEDSNQPQHF & 10.255 & 0.007 & $p<0.0001$ & none & & & \\
\hline & & CASSYRQAGEAFF & 1.695 & 0.011 & $p<0.0001$ & CASSLRQGEAFF & NLVPMVATV & pp65 & HCMV \\
\hline \multirow[t]{2}{*}{597} & $\mathrm{RE}$ & CASTTEPGTPNTGELFF & 1.873 & 0.006 & $p<0.0001$ & none & & & \\
\hline & & CASSFFTNTEAFF & 24.437 & 0.015 & $p<0.0001$ & CASSFFGNTEAFF & KLGGALQAK & $\mathrm{IE} 1$ & HCMV \\
\hline \multirow[t]{2}{*}{81} & TSC & CASSEWSGRASLDTQYF & 1.795 & n.a. & n.d. & none & & & \\
\hline & & CASSTTGMGSPLHF & 11.795 & n.a. & n.d. & CASSPTGGGSPLHF & GILGFVFTL & M & $\begin{array}{l}\text { Influenza } \\
\text { A }\end{array}$ \\
\hline \multirow[t]{2}{*}{100} & TSC & CSALDGNRRRNQPQHF & 1.308 & n.a. & n.d. & none & & & \\
\hline & & CASSRGSVAPGELFF & 20.630 & n.a. & n.d. & CASSKGSVAPGELFF & GLCTLVAML & BMLF1 & EBV \\
\hline \multirow[t]{2}{*}{106} & TSC & CASSQELTGLAGYTF & 8.797 & n.a. & n.d. & none & & & \\
\hline & & CASSKQGSTEAFF & 4.134 & n.a. & n.d. & CASSKQGSTEAFF & GLCTLVAML & BMLF1 & EBV \\
\hline \multirow[t]{2}{*}{275} & TSC & CASSEIVGQGDHF & 0.629 & n.a. & n.d. & none & & & \\
\hline & & CASSFGTTEQYF & 0.943 & n.a. & n.d. & CASSFGGT-QYF & GILGFVFTL & $\mathrm{M}$ & $\begin{array}{l}\text { Influenza } \\
\text { A }\end{array}$ \\
\hline \multirow[t]{2}{*}{460} & TSC & CASSPGTGGLFFSSGELF & 0.645 & 0.0 & n.d. & none & & & \\
\hline & & CASSDPWYEQF & 1.424 & 0.003 & $p<0.0001$ & CASSDS-YEQYF & KLGGALQAK & $\mathrm{IE} 1$ & HCMV \\
\hline \multirow[t]{2}{*}{462} & TSC & CSARDYRNPKVTEAFF & 1.673 & 0.344 & $p<0.0001$ & none & & & \\
\hline & & CASSQDGQGDQPQHF & 6.201 & 0.027 & $p<0.0001$ & CASSQ-GQGDQPQHF & KLGGALQAK & $\mathrm{IE} 1$ & HCMV \\
\hline \multirow[t]{2}{*}{524} & TSC & CALLRPGPSYEQYF & 2.151 & 0.003 & $p<0.0001$ & none & & & \\
\hline & & CASSLIDGYNEQFF & 2.912 & 0.005 & $p<0.0001$ & CASSLISGYNEQFF & KLGGALQAK & $\mathrm{IE} 1$ & HCMV \\
\hline \multirow[t]{2}{*}{595} & TSC & CATSDLDGREAGELFF & 2.442 & 0.001 & $p<0.0001$ & none & & & \\
\hline & & CASSPLVDNYGYTF & 0.471 & 0.001 & $p<0.0001$ & CASSGLVDNGYTF & KLGGALQAK & $\mathrm{IE} 1$ & HCMV \\
\hline
\end{tabular}

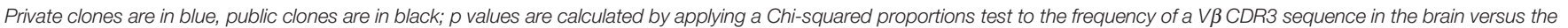

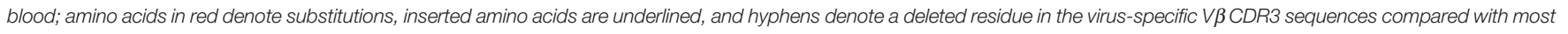
abundant $V \beta C D R 3$ sequences in the brain; n.a, not available; n.d, not determined.

overlap between the sampled brain and blood repertoires from the two surgeries, and found $59 \mathrm{~V} \beta \mathrm{CDR} 3$ sequences that are common to the four samples (Figure S4). We focused on the sequences whose frequency differed significantly between either blood from the first and second surgeries or between brain tissue from the first and second surgeries. As shown in Table 3, the frequencies of 14 public and private $\mathrm{V} \beta$ clonotypes were significantly higher in brain tissue from the second surgery compared with brain tissue from the first surgery. The frequency of only one V $\beta$ clonotype significantly increased in both the blood and the brain; this clone was among the top 50 in each sample (Table 3).

\section{Changes in the TCR Repertoire in the Blood After Epilepsy Surgery}

We collected blood from Patient 595 during a clinic visit five months after the surgery; at this time the patient was reported to be seizure free although still taking anti-seizure medications. We obtained TCR V $\beta$ CDR3 sequences from genomic DNA, and compared them to the TCR V $\beta$ CDR3 sequences in blood collected at the time of the surgery and to the top 50 TCR V $\beta$ CDR3 sequences in brain tissue from the surgery. Thirty-four of the top 50 brain $\mathrm{V} \beta$ clonotypes were present in both blood samples, and the frequency of 18 of these V $\beta$ clonotypes had significantly decreased in the blood after the surgery, while the remaining 16 had not changed (Table 4; Figure S5). This suggests that removal of the source of seizure activity may have led to the contraction of specific T cell clones. However, the overall clonality index of the TCR repertoire in the blood had increased from 0.0183 to 0.0747 suggesting that there were other clones that may have expanded. Comparing the top 50 V $\beta$ CDR3 sequences from the post-surgery blood draw with the sampled repertoire from the pre-surgery blood draw revealed five overlapping clones three of which had significantly expanded; the relative frequency of the remaining two clones that were also among the top 50 clones from the pre-surgery blood draw had not changed (Figures 4A, B). The V $\beta$ CDR3 amino acid sequences of four of the $\mathrm{V} \beta$ clonotypes were very similar to $\mathrm{V} \beta$ CDR3 sequences that recognize the same epitope from HCMV restricted on HLA $A^{\star} 03$; the sequence of the fifth $\mathrm{V} \beta$ clonotype was a perfect match (Figure 4B). As previously mentioned, we had determined that Patient 595 carries the HLA A*03 allele (Table S2). We characterized the PBMCs in pre- and postsurgery blood by mass cytometry and found that there was an approximately five-fold increase in CD8 transitional memory $\mathrm{T}$ cells (Figure 4C; Figure S6). In addition to the expanded V $\beta$ clonotypes we found that the three most abundant $\mathrm{V} \beta$ clonotypes in the sample of post-surgery blood were not found in the pre-surgery blood nor the brain (Figures 4D, E). The depth of coverage of the post-surgery blood was higher than the pre-surgery blood (87,551 versus 372,380 different TCR V $\beta$ 
TABLE 3 | Changes in the frequencies of T cell clonotypes in blood and brain specimens from the first and second surgeries.

\begin{tabular}{|c|c|c|c|c|c|c|c|c|}
\hline \multirow[t]{2}{*}{ V $\beta$ CDR3 } & \multirow{2}{*}{$\frac{\text { Blood }}{460 \rightarrow 524}$} & \multirow[b]{2}{*}{$p$ value } & \multirow{2}{*}{$\frac{\text { Brain }}{460 \rightarrow 524}$} & \multirow[b]{2}{*}{$p$ value } & \multicolumn{2}{|c|}{ Top 50 Blood } & \multicolumn{2}{|c|}{ Top 50 Brain } \\
\hline & & & & & 460 & 524 & 460 & 524 \\
\hline CASSSRRINQPQHF & $\uparrow$ & 0.0127 & $\uparrow$ & $<0.0001$ & $\checkmark$ & $\checkmark$ & $\checkmark$ & $\checkmark$ \\
\hline CASSKGVRAMSGNTIYF & $\uparrow$ & 0.032 & n.c. & 0.2967 & & & & \\
\hline CASSWGLTGGVSEQFF & $\uparrow$ & 0.0352 & n.c. & 0.4138 & $\checkmark$ & $\checkmark$ & $\checkmark$ & $\checkmark$ \\
\hline CASSVGRLAGGTYEQYF & $\uparrow$ & 0.0423 & n.c. & 0.1437 & & & & \\
\hline CASSVNYSNQPQHF & $\uparrow$ & 0.0001 & n.c. & 0.5407 & $\checkmark$ & $\checkmark$ & $\checkmark$ & $\checkmark$ \\
\hline CACPDRGSGNTIYF & $\uparrow$ & 0.0002 & n.c. & 0.7153 & & $\checkmark$ & & \\
\hline CASSLVAGARGYTF & $\uparrow$ & 0.032 & n.c. & 0.7153 & & & & \\
\hline CASSTWGRTYEQYF & n.c. & 0.5196 & $\uparrow$ & 0.0496 & & & & \\
\hline CASSHSGGNYEQYF & n.c. & 0.7521 & $\uparrow$ & 0.0001 & & & $\checkmark$ & $\checkmark$ \\
\hline CASSLDSSGGANNEQFF & n.c. & 0.7945 & $\uparrow$ & 0.0014 & $\checkmark$ & $\checkmark$ & & $\checkmark$ \\
\hline CASSWTGLGAYEQYF & n.c. & 0.9181 & $\uparrow$ & 0.0207 & $\checkmark$ & $\checkmark$ & $\checkmark$ & $\checkmark$ \\
\hline CASSEWLNQPQHF & n.c. & 0.9314 & $\uparrow$ & 0.0006 & $\checkmark$ & $\checkmark$ & & $\checkmark$ \\
\hline CASSLGPGGSYEQYF & n.c. & 0.4426 & $\uparrow$ & $<0.0001$ & $\checkmark$ & $\checkmark$ & $\checkmark$ & $\checkmark$ \\
\hline CASSSGGAPANEKLFF & n.c. & 0.6341 & $\uparrow$ & $<0.0001$ & & & & $\checkmark$ \\
\hline CASSWTYKVNEQFF & n.c. & 0.9181 & $\uparrow$ & 0.0157 & $\checkmark$ & & & $\checkmark$ \\
\hline CASRWFSVYEQYF & n.c. & 0.2231 & $\uparrow$ & 0.0185 & $\checkmark$ & $\checkmark$ & $\checkmark$ & $\checkmark$ \\
\hline CASSLKTFSSGEQYF & n.c. & 0.7981 & $\uparrow$ & 0.0203 & & & & $\checkmark$ \\
\hline CASSINGASHHTNEKLFF & n.c. & 0.9761 & $\uparrow$ & 0.0496 & & & & \\
\hline CASRPSGLSGEQYF & $\downarrow$ & 0.0018 & $\uparrow$ & $<0.0001$ & $\checkmark$ & $\checkmark$ & $\checkmark$ & $\checkmark$ \\
\hline CASSLSGGNYEQYF & $\downarrow$ & 0.0066 & $\uparrow$ & 0.0006 & $\checkmark$ & & $\checkmark$ & $\checkmark$ \\
\hline CASSLGDNYGYTF & $\downarrow$ & 0.0005 & n.c. & 0.7153 & $\checkmark$ & $\checkmark$ & & \\
\hline CASSLDGGGSGYEQYF & $\downarrow$ & 0.0276 & n.c. & 0.7153 & $\checkmark$ & $\checkmark$ & & \\
\hline CASRKQGPRVEQYF & $\downarrow$ & 0.0004 & n.c. & 0.2967 & $\checkmark$ & $\checkmark$ & & \\
\hline
\end{tabular}

Private clonotypes are in blue; public clonotypes are in black; $\uparrow$ increase in frequency; $\downarrow$ decrease in frequency.

$\checkmark$ present in the top 50 blood or brain clonotypes; n.c, no change.

CDR3 amino acid sequences), thus we cannot exclude the possibility that the sampling of the TCR repertoire in the presurgery blood was not sufficient to capture these clones.

\section{Public and Private CD8 ${ }^{+}$T Cell Clones With an Effector Phenotype in Epileptogenic Brain}

A month after we had collected the blood sample, Patient 595 developed seizures, which progressively worsened leading to a

TABLE 4 | Decrease in frequency of the top 50 brain clonotypes in post-surgery blood.

\begin{tabular}{lcc}
\hline $\mathbf{v} \beta$ CDR3 & pre $\rightarrow$ post & p value \\
\hline CAMDKGEAFF & $\downarrow$ & $<0.0001$ \\
CASRVIYGYTF & $\downarrow$ & $<0.0001$ \\
CASSLREARWNTQYF & $\downarrow$ & $<0.0001$ \\
CASSPRTANNEQFF & $\downarrow$ & $<0.0001$ \\
CASSSTKREAVQETQYF & $\downarrow$ & $<0.0001$ \\
CSAWTGSMNTEAFF & $\downarrow$ & $<0.0001$ \\
CASSLGAGHGYTF & $\downarrow$ & 0.0001 \\
CASSPLNNEQFF & $\downarrow$ & 0.0012 \\
CASSLSGGFTGELFF & $\downarrow$ & 0.0024 \\
CASSLGDYGYTF & $\downarrow$ & 0.0044 \\
CALREVDGYTF & $\downarrow$ & 0.0045 \\
CASDPGELFF & $\downarrow$ & 0.0045 \\
CASSPAGVSPLHF & $\downarrow$ & 0.0076 \\
CAIRDGQGGYEQYF & $\downarrow$ & 0.0079 \\
CAILKSLDGYTF & $\downarrow$ & 0.015 \\
CASLTITGQGFYEQYF & $\downarrow$ & 0.0165 \\
CASSLAGRLAF & $\downarrow$ & 0.0228 \\
CASSLAPSGYNEQFF & $\downarrow$ & 0.0379
\end{tabular}

Private clonotypes are in blue; public clonotypes are in black; $\downarrow$ decrease in frequency. second surgery six months later to remove another tuber from a different area of the brain. We received a portion of this tuberous tissue, and isolated a fresh leukocyte fraction for single cell RNA sequencing. Bar-coded libraries were made to enumerate gene transcripts and determine TCR sequences. Although we expected to obtain fewer TCR sequences (30), we chose this approach in order to determine the phenotype of the most frequently expressed TCR V $\beta$ clonotypes, and to obtain both TCR V $\alpha$ and $V \beta$ sequences for future synthesis and cloning of the receptors. We obtained RNA transcript data from 2,694 cells of which 391 were T cells (Table S4). To compare with our existing TCR sequence data from this patient we only considered barcodes assigned to one unique $\mathrm{V} \beta$ chain sequence, which corresponded to $382 \mathrm{~T}$ cells expressing 323 different $\mathrm{V} \beta$ chain sequences (Table S4). More than one V $\beta$ was assigned to seven barcodes, and only a $\mathrm{V} \alpha$ chain was assigned to two barcodes (Table S4). As shown in Figure 4E, two of the most abundant V $\beta$ clonotypes found in the blood six months before the second surgery were among the $\mathrm{T}$ cells isolated from the resected tuber. We also found that 14 of the top $50 \mathrm{~V} \beta$ clonotypes in brain tissue from the first surgery were also among the $\mathrm{T}$ cells isolated from the second resected tuber (Figure S7; Table 5). The frequencies of two of the overlapping V $\beta$ clonotypes were significantly higher in the sampled repertoire from the second surgery, while a third $\mathrm{V} \beta$ clonotype had decreased; frequencies of the remaining $\mathrm{V} \beta$ clonotypes had not changed significantly (Table 5). The two V $\beta$ clonotypes that had increased were the two most abundant comprising $\sim 4.5 \%$ of the T cells (Table S4). We combined the TCR and transcript data to determine the phenotype of these two clones, and it appears, based on transcription factor expression 
A

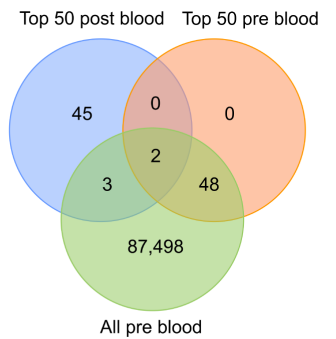

B

B CDR3 CASSLVQGYNEQFF CASSLGGTEAFF CASGGVNTEAFF CASSQGAHSPLHF CASSLATSGSSYEQYF n.c.$$
\text { Pre } \rightarrow \text { Post } \quad p
$$$$
\text { p value Viral specific CDR3 }
$$$$
\uparrow \quad<0.0001 \text { CASSL-SGYNEQFF }
$$

HCMV Epitope

KLGGALQAK

$\uparrow \quad<0.0001$ CASSLGGTEAFF

$<0.0001$ CASS SGGVNTEAFF

KLGGALQAK

KLGGALQAK

0.1457 CASSQGGNSPLHF KLGGALQAK

0.3758 CASSLVAT-GLSYEQYF KLGGALQAK
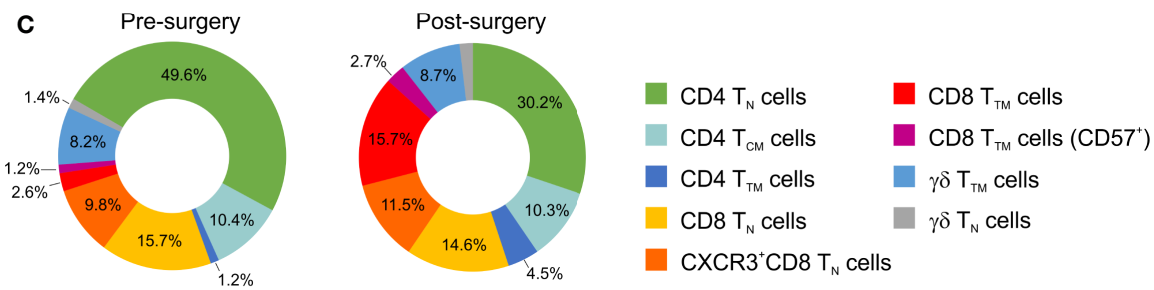

D

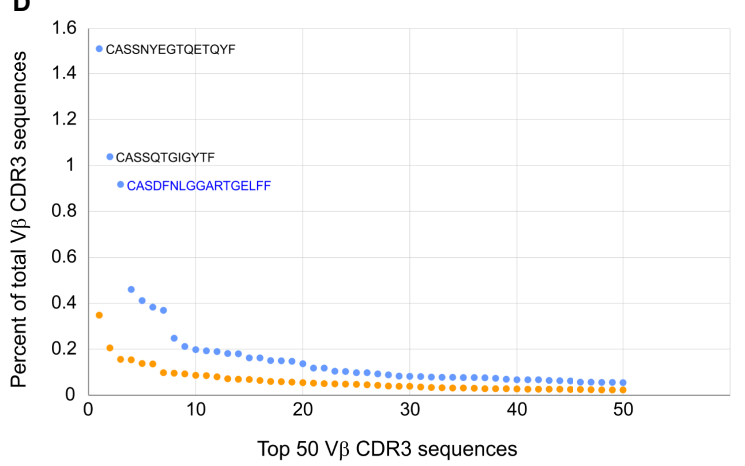

E

\begin{tabular}{lcllllll}
\multicolumn{1}{c}{ Blood } & \multicolumn{9}{c}{ Brain } & & \\
\multicolumn{1}{c}{ V $\beta$ CDR3 } & Pre $(\%)$ & Post $(\%)$ & 1 st surgery $(\%)$ & 2nd surgery $(\%)$ & Viral specific CDR3 & HCMV Epitope \\
CASSNYEGTQETQYF & 0.000 & 1.512 & 0.000 & 0.512 & CASSFY-GTQETQYF & KLGGALQAK \\
CASSQTGIGYTF & 0.000 & 1.037 & 0.000 & 0.000 & CASSQTGVGYTF & KLGGALQAK \\
CASDFNLGGARTGELFF & 0.000 & 0.917 & 0.000 & 0.256 & not found &
\end{tabular}

FIGURE 4 | Longitudinal profiling of T cells in a TSC patient. (A) Venn diagram showing the overlap between the top 50 clonotypes present in the blood 5 months after surgery (post blood) and clonotypes present in the blood just prior to the surgery (pre blood). (B) V $\beta$ CDR3 sequences of the five overlapping $T$ cell clonotypes: the frequency of the three that were not among the top 50 clonotypes in the pre blood are significantly higher in the post blood. Comparison of the five V $\beta$ CDR3 sequences to CDR3 sequences that recognize the same HCMV epitope restricted on HLA $A^{*} 03$. Amino acids in red are substitutions and underlined residues are additions; a dashed line indicates a deletion. (C) Donut plots showing the relative frequency of $\mathrm{T}$ cell subtypes in $\mathrm{CD} 45^{+} \mathrm{CD} 3^{+}$cells from pre- and post-surgery blood. $T_{N}$, naiive $T$ cells; $T_{T M}$, transitional memory $T$ cells; $T_{C M}$, central memory $T$ cells. (D) Comparison of the frequencies of the top 50 clonotypes in pre- and postsurgery blood showing that there are three dominant clonotypes in the post blood reflecting an increase in the clonality score from 0.018 (Table 1) to 0.075 . The two public $V \beta$ CDR3 sequences are in black and the private $V \beta$ CDR3 sequence is in blue. (E) The three dominant clonotypes in the post-surgery blood were not found in the blood or brain from the first surgery, but were found in the single cell TCR sequences from the second surgery. The two public V $\beta$ CDR3 sequences are similar to virus specific $V \beta C D R 3$ sequences restricted on $\mathrm{HLA}-\mathrm{A}^{*} 03$. Amino acids in red are substitutions and a dashed line indicates a deletion.

that they are primarily CD8 effector T cells (Figure 5). This would imply that at the time of the second surgery there was an active immune response occurring in the brain of this patient.

\section{DISCUSSION}

We have quantified immune cell transcripts in brain tissue that was removed to treat children with medically refractory seizures, and assigned genes to $\mathrm{T}$ cells and microglia/macrophages based on published single cell RNAseq data. Unsupervised clustering of the data revealed a spectrum of involvement of innate and adaptive immune cells with a subset of patients having a higher inflammatory signature. Two RE cases led this high inflammation group, which also included TSC, FCD, HME and PAIS cases. The other four RE cases in the study cohort clustered with TSC and FCD cases that had lower $\mathrm{z}$ scores for immune gene expression, likely reflecting fewer $\mathrm{T}$ cells and microglia in the resected tissue that was analyzed. This suggests that the extent of $\mathrm{T}$ cell involvement is variable between patients with the same diagnosis even in the case of RE. This variability did not 
TABLE 5 | Changes in the frequency of T cell clonotypes in brain tissue from the first and second resective surgeries performed on TSC patient 595.

\begin{tabular}{lcc}
\hline CDR3 & $\mathbf{1}^{\text {st }} \rightarrow \mathbf{2}^{\text {nd }}$ surgery & p value \\
\hline CATSTGGRERPGELFF & $\uparrow$ & $\mathrm{p}<0.0001$ \\
CASSLAPSGYNEQFF & $\uparrow$ & $\mathrm{p}<0.0001$ \\
CSAPVRLALFYEQYF & $\downarrow$ & 0.021 \\
CASSPAGVSPLHF & n.c. & 0.386 \\
CAMDKGEAFF & n.c. & 0.972 \\
CASSPALAGGFTGELFF & n.c. & 0.559 \\
CASSPLNNEQFF & n.c. & 0.726 \\
CALREVDGYTF & n.c. & 0.785 \\
CASTLAGVATF & n.c. & 0.785 \\
CASSLILIYGYTF & n.c. & 0.799 \\
CASSPLVDNYGYTF & n.c. & 0.908 \\
CASSLGDYGYTF & n.c. & 0.609 \\
CALGGLGELFF & n.c. & 0.811 \\
CASSVAGYGYTF & n.c. & 0.966 \\
\hline
\end{tabular}

Private clonotypes are in blue; public clonotypes are in black;

$\uparrow$ increase in frequency; $\downarrow$ decrease in frequency; n.c. no change.

appear to be related to the gender or age of the patient or seizure duration, at least in our study cohort.

We obtained TCR V $\beta$ sequencing from 12 patients with the highest $\mathrm{T}$ cell gene expression signature. From the clonality indices and the frequency of the top 50 we conclude that $\mathrm{T}$ cells are clonally focused in brain tissue from all but one of the surgeries (case 275) implying that there was an antigen driven immune response in the epileptogenic area of the brain that was removed. We also selected a sample of brain and blood from surgery case 460 , which had a much lower inflammatory signature, but came from a patient who was operated on again 11 months later (surgery case 524). The $\mathrm{T}$ cell gene expression signature was higher in resected brain tissue from the second surgery, and the clonality score from the second surgery was double that of the first surgery indicating that $\mathrm{T}$ cells in the affected brain from the second surgery were more clonally focused. One public V $\beta$ clonotype was highly significantly increased in brain tissue from the second surgery, and may explain in part the increased clonality index.

We previously found that some of the most abundant $\mathrm{V} \beta$ clonotypes in brain tissue from 14 RE patients were public (31). In the present study a public $\mathrm{V} \beta$ clonotype was the most abundant $\mathrm{T}$ cell clone in ten of the cases. Moreover, the V $\beta$ CDR3 sequence of the most abundant public V $\beta$ clonotypes were strikingly similar to V $\beta$ CDR3 sequences that have been shown experimentally to recognize viral epitopes. We determined that two of the patients, TSC patient 595 and RE patient 597 carry HLA class I alleles that might present HCMV antigens. The V $\beta$ CDR3 sequences in the abundant $\mathrm{T}$ cell clonotypes in the brain and blood of these two patients are very similar, and in one case identical, to ones that bind HCMV peptides, suggesting that the $\mathrm{T}$ cell clones may have arisen due to exposure to HCMV. We have no information whether the patients are seropositive for HCMV, although individuals with latent HCMV may not necessarily have detectable antibodies (32).

Five months after TSC patient 595 underwent resective surgery we found that the frequency about a third of the top 50 brain V $\beta$ clonotypes had decreased in the blood compared with the blood collected the time of the surgery. This suggests that at least some of the $\mathrm{T}$ cell clones found in the brain had contracted in the periphery after removal of the brain area associated with seizure activity and inflammation. However, other public $\mathrm{V} \beta$ clonotypes had expanded along with an increase in circulating transitional memory effector CD8 T cells, suggesting that the expanded V $\beta$ clonotypes could be antigen experienced CD8 T cells. The same CD8 T cell subtype was also found in the blood and resected brain tissue from Patient 597, an RE case. Based on the clinical notes, Patient 595 was seizure free and there was no report of an infection at the time the post-surgery blood was drawn. We speculate that a subclinical viral infection or an asymptomatic reactivation of a latent virus possibly HCMV may have occurred, since the V $\beta$ CDR3 sequences of the public clones were very similar to ones that recognize an immunodominant HCMV epitope. In our analysis of future cases, we plan to use epitope specific pentamers to directly determine whether $\mathrm{T}$ cells isolated from resected brain tissue recognize $\mathrm{EBV}, \mathrm{HCMV}$, or influenza $\mathrm{A}$ antigens, and to subsequently screen for the presence of viral sequences in resected brain tissue. In multiple sclerosis patients, EBV reactive $T$ cells have been found in perivascular spaces in the brain, and in direct contact with EBV-infected B cells (33).

The two RE cases that had the highest inflammatory signatures and clonality scores appear to represent divergent cases of $\mathrm{T}$ cell involvement in the disease in as much as in Patient 500 a private possibly autoreactive $\mathrm{T}$ cell clone comprised $\sim 10$ percent of the brain repertoire whereas in Patient 597 a public clone possibly reactive to HCMV comprised $\sim 24$ percent of the T cells. Herpesviruses have long been considered a trigger for RE and the presence of EBV and HCMV in RE brain tissue has been reported (34-38). Further it was reported that ganciclovir treatment of a patient diagnosed with early stage RE led to a cessation of seizures, directly implicating a herpesvirus in disease pathogenesis (39). HCMV and EBV are very prevalent pathogenic viruses, although children who are exposed to HCMV and EBV generally do not experience any symptoms $(40,41)$. Both viruses persist in a latent state in monocytes and memory B cells respectively $(42,43)$, and it has been shown that transition of monocytes to macrophages leads to reactivation of latent HCMV (42). Therefore, it is conceivable that HCMV could be carried into the brain by monocytes responding to seizuredriven brain inflammation, leading to viral antigen reexpression, and mobilization of HCMV reactive $\mathrm{T}$ cells, which could in turn result in bystander activation of autoreactive $\mathrm{T}$ cells. Activated T cells could permanently alter brain circuitry by directly or indirectly damaging neurons (44-47). Combining single cell RNA expression with TCR sequencing allowed us to definitively show that the dominant private and public $\mathrm{V} \beta$ clonotypes in the brain of a TSC patient were activated CD8 T cells. Whether the private V $\beta$ clonotype was directed against an infectious agent or constituted an autoreactive $\mathrm{T}$ cell clone is not known. In TSC, FCDIIA/B, and HME clonally restricted private $\mathrm{T}$ cells might be directed against neoantigens expressed by dysmorphic neurons and balloon cells. We found $\mathrm{T}$ cells in close proximity to dysmorphic cells in sections from TSC brain tissue with a high TCR clonality index. 
A
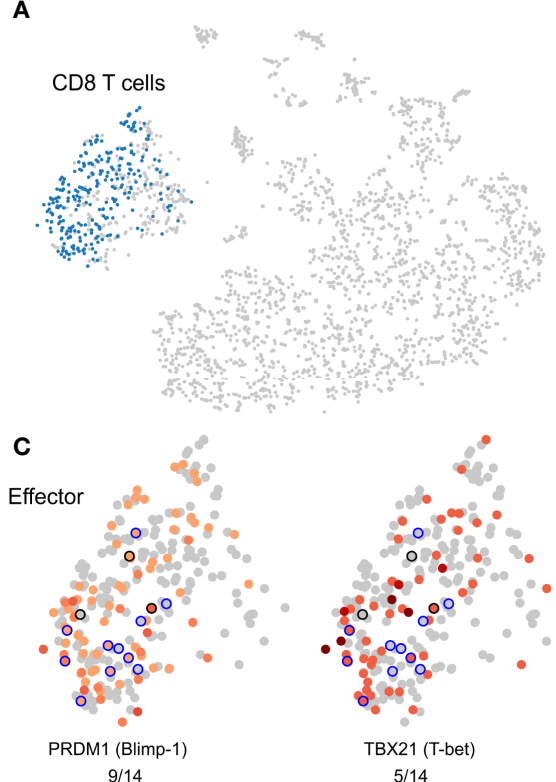

$9 / 14$
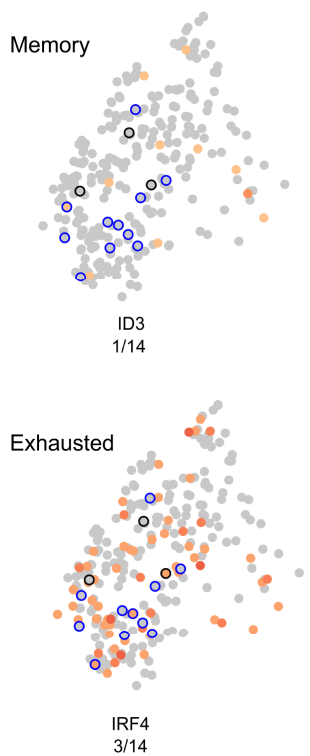

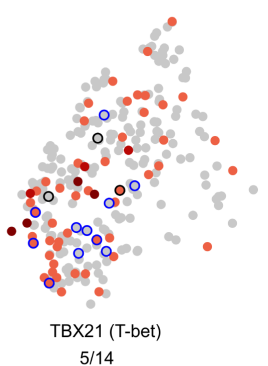

$5 / 14$
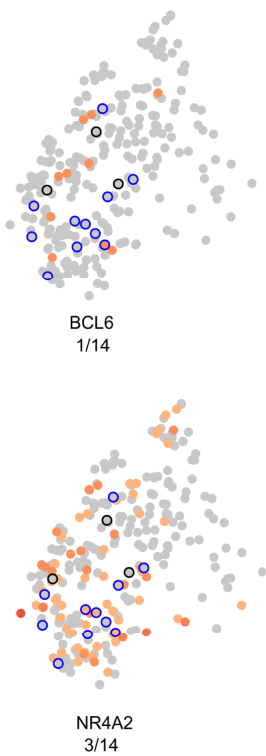
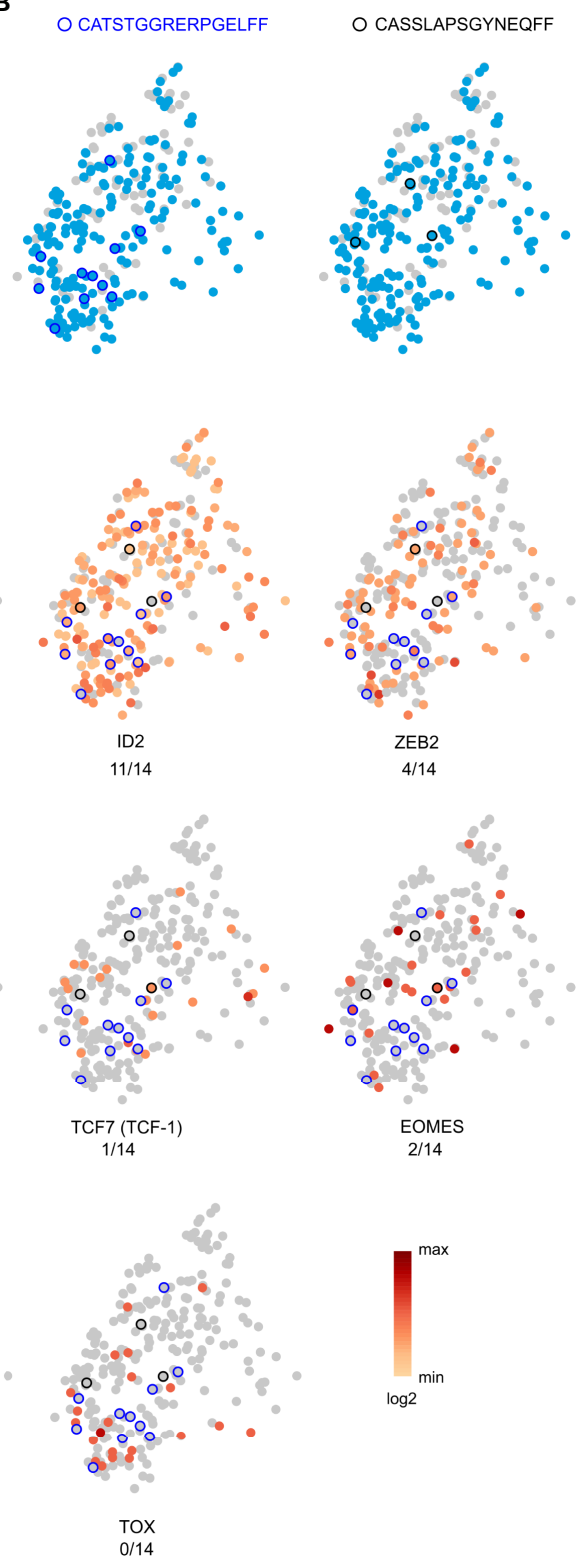

FIGURE 5 | Effector phenotype of public and private TCR clonotypes. (A) t-SNE plot, based on single cell RNA expression data, of brain-infiltrating leukocytes from Patient 595's second surgery. CD8 T cells are colored blue. (B) Location within the cluster of T cells of the two clonotypes that overlap between the post-surgery blood and brain (Figure 4). Clonotypes are circled in black. (C) Single cell heat maps for transcription factors that define effector, memory, and exhausted CD8 T cells. Of the $11 \mathrm{~T}$ cells that express the two TCRs, the majority of the cells likely correspond to effector T cells.

The TSC cases in our study cohort partitioned into either a higher or lower inflammatory group. Why there appears to be a greater involvement of the immune system in the brain in some TSC cases and not in others is not clear. It would most likely depend on the HLA alleles carried by the patient, but it may also be related to the TSC mutation itself; the mTOR pathway has been clearly implicated in the regulation of immune cell function (48). A somatic mutation arising early in gestation might be found in hematopoietic stem cells resulting in over-activation of the mTOR pathway in lymphoid and myeloid lineages. The type of mutation whether in TSC1 or TSC2 and the degree of mTOR over-activation could impact homeostatic immune system function. High mTOR activity enhances effector $\mathrm{T}$ cell effector function, promotes pro-inflammatory macrophages but suppresses the development of regulatory $\mathrm{T}$ cells $(49,50)$. In an induced seizure model, infusing regulatory $\mathrm{T}$ cells was found to reduce seizure activity (10). It is possible that the ameliorative effects on seizures of the rapamycin-based drug, everolimus, could in part be due to its immune modulatory action (51). 
In conclusion we present evidence for $\mathrm{T}$ cell mediated immune responses in pediatric cases of intractable epilepsy where adaptive immunity may not have been hitherto considered a component of the disorder. Recently, new definitions of epilepsy cases that involve autoimmunity have been proposed in which the distinction is drawn between acute seizures secondary to autoimmune encephalitis as in the case of antibody-mediated encephalitides, and autoimmune-associated epilepsy for example RE (4). Based on our study cohort the latter definition may also include cases of FCD, TSC, and HME, and may support the use of modulators of adaptive immunity as potential adjunctive treatments (52-56).

\section{DATA AVAILABILITY STATEMENT}

The original contributions presented in the study are publicly available. This data can be found here: Adaptive Biotechnology immuneAccess ${ }^{\circledR}:$ https://clients.adaptivebiotech.com/pub/ chang-2021-fi; DOI 10.21417/JWC2021FI NCBI Gene Expression Omnibus: GSE168741.

\section{ETHICS STATEMENT}

The studies involving human participants were reviewed and approved by UCLA Institutional Review Board (IRB no. 18-001048). Written informed consent to participate in this study was provided by the participants' parent/legal guardian.

\section{AUTHOR CONTRIBUTIONS}

JC organized and coordinated the collection of clinical specimens and data, prepared PBMCs, carried out immunocytochemistry,

\section{REFERENCES}

1. Bauer J, Becker AJ, Elyaman W, Peltola J, Ruegg S, Titulaer MJ, et al. Innate and adaptive immunity in human epilepsies. Epilepsia (2017) 58 Suppl 3:5768. doi: 10.1111/epi.13784

2. Bartolini L, Libbey JE, Ravizza T, Fujinami RS, Jacobson S, Gaillard WD. Viral triggers and inflammatory mechanisms in pediatric epilepsy. Mol Neurobiol (2019) 56:1897-907. doi: 10.1007/s12035-018-1215-5

3. Ahlers FS, Benros ME, Dreier JW, Christensen J. Infections and risk of epilepsy in children and young adults: A nationwide study. Epilepsia (2019) 60:275-83. doi: 10.1111/epi.14626

4. Steriade C, Britton J, Dale RC, Gadoth A, Irani SR, Linnoila J, et al. Acute symptomatic seizures secondary to autoimmune encephalitis and autoimmune-associated epilepsy: Conceptual definitions. Epilepsia (2020) 61:1341-51. doi: 10.1111/epi.16571

5. D'Gama AM, Woodworth MB, Hossain AA, Bizzotto S, Hatem NE, LaCoursiere CM, et al. Somatic mutations activating the mTOR pathway in dorsal telencephalic progenitors cause a continuum of cortical dysplasias. Cell Rep (2017) 21:3754-66. doi: 10.1016/j.celrep.2017.11.106

6. Salussolia CL, Klonowska K, Kwiatkowski DJ, Sahin M. Genetic etiologies, diagnosis, and treatment of tuberous sclerosis complex. Annu Rev Genomics Hum Genet (2019) 20:217-40. doi: 10.1146/annurev-genom083118-015354 and assisted with manuscript preparation. SR prepared PBMCs and BILs, and assisted with specimen collection. EF-K carried out the NanoString ${ }^{\circledR}$ assays. SKL, ML, SML, RL, PL, $\mathrm{KP}, \mathrm{HW}, \mathrm{GM}$, and AF provided surgical specimens and clinical data. NS provided diagnostic imaging data, and HV provided tissue sections and pathology reports. GO designed the study, analyzed the data, and wrote the paper with input from the coauthors. All authors contributed to the article and approved the submitted version.

\section{ACKNOWLEDGMENTS}

This study was funded by NIH grant NS107884 and The RE Children's Project. CytTOF was carried out by The Jonsson Comprehensive Cancer Center Janis V. Giorgi Cytometry Core Facility, RNA sequencing was carried out by The Technology Center for Genomics, Bioinformatics, Department of Pathology and Laboratory Medicine, and HLA typing by The UCLA Immunogenetics Center, Department of Pathology and Laboratory Medicine. The nanoString ${ }^{\circledR}$ assays were performed at the UCLA IMT Core/Center for Systems Biomedicine, which is supported by NIH grant P30DK041301. Post-surgery blood draw involved The Clinical and Translational Research Center, which is supported by NIH National Center for Advancing Translational Science (NCATS) UCLA CTSI Grant Number UL1TR001881.

\section{SUPPLEMENTARY MATERIAL}

The Supplementary Material for this article can be found online at: https://www.frontiersin.org/articles/10.3389/fimmu.2021. 664344/full\#supplementary-material

7. Boer K, Jansen F, Nellist M, Redeker S, van den Ouweland AM, Spliet WG, et al. Inflammatory processes in cortical tubers and subependymal giant cell tumors of tuberous sclerosis complex. Epilepsy Res (2008) 78:7-21. doi: 10.1016/j.eplepsyres.2007.10.002

8. Iyer A, Zurolo E, Spliet WG, van Rijen PC, Baayen JC, Gorter JA, et al. Evaluation of the innate and adaptive immunity in type I and type II focal cortical dysplasias. Epilepsia (2010) 51:1763-73. doi: 10.1111/j.15281167.2010.02547.x

9. Blumcke I, Thom M, Aronica E, Armstrong DD, Vinters HV, Palmini A, et al. The clinicopathologic spectrum of focal cortical dysplasias: a consensus classification proposed by an ad hoc Task Force of the ILAE Diagnostic Methods Commission. Epilepsia (2011) 52:158-74. doi: 10.1111/j.15281167.2010.02777.x

10. Xu D, Robinson AP, Ishii T, Duncan DS, Alden TD, Goings GE, et al. Peripherally derived $\mathrm{T}$ regulatory and gammadelta $\mathrm{T}$ cells have opposing roles in the pathogenesis of intractable pediatric epilepsy. J Exp Med (2018) 215:1169-86. doi: 10.1084/jem.20171285

11. Owens GC, Garcia AJ, Mochizuki AY, Chang JW, Reyes SD, Salamon N, et al. Evidence for innate and adaptive immune responses in a cohort of intractable pediatric epilepsy surgery patients. Front Immunol (2019) 10:121. doi: 10.3389/fimmu.2019.00121

12. Cibrian D, Sanchez-Madrid F. CD69: from activation marker to metabolic gatekeeper. Eur J Immunol (2017) 47:946-53. doi: 10.1002/eji.201646837 
13. Le S, Josse J, Husson F. FactoMineR: An R package for multivariate analysis. J Stat Softw (2008) 25:1-18. doi: 10.18637/jss.v025.i01

14. Lefranc MP, Pommie C, Ruiz M, Giudicelli V, Foulquier E, Truong L, et al. IMGT unique numbering for immunoglobulin and $\mathrm{T}$ cell receptor variable domains and Ig superfamily V-like domains. Dev Comp Immunol (2003) 27:55-77. doi: 10.1016/S0145-305X(02)00039-3

15. Harden JL, Hamm D, Gulati N, Lowes MA, Krueger JG. Deep sequencing of the T-cell receptor repertoire demonstrates polyclonal T-cell infiltrates in psoriasis. F1000Res (2015) 4:460. doi: 10.12688/f1000research.6756.1

16. Campbell I. Chi-squared and Fisher-Irwin tests of two-by-two tables with small sample recommendations. Stat Med (2007) 26:3661-75. doi: 10.1002/sim.2832

17. Bagaev DV, Vroomans RMA, Samir J, Stervbo U, Rius C, Dolton G, et al. VDJdb in 2019: database extension, new analysis infrastructure and a T-cell receptor motif compendium. Nucleic Acids Res (2020) 48:D1057-62. doi: 10.1093/nar/gkz874

18. Owens GC, Erickson KL, Malone CC, Pan C, Huynh MN, Chang JW, et al. Evidence for the involvement of gamma delta $\mathrm{T}$ cells in the immune response in Rasmussen encephalitis. J Neuroinflamm (2015) 12:134. doi: 10.1186/ s12974-015-0352-2

19. Chen TJ, Kotecha N. Cytobank: providing an analytics platform for community cytometry data analysis and collaboration. Curr Top Microbiol Immunol (2014) 377:127-57. doi: 10.1007/82_2014_364

20. Chen H, Lau MC, Wong MT, Newell EW, Poidinger M, Chen J. Cytofkit: A Bioconductor package for an integrated mass cytometry data analysis pipeline. PloS Comput Biol (2016) 12:e1005112. doi: 10.1371/journal.pcbi.1005112

21. Owens GC, Chang JW, Huynh MN, Chirwa T, Vinters HV, Mathern GW. Evidence for resident memory $\mathrm{T}$ cells in Rasmussen Encephalitis. Front Immunol (2016) 7:64. doi: 10.3389/fimmu.2016.00064

22. Newman AM, Liu CL, Green MR, Gentles AJ, Feng W, Xu Y, et al. Robust enumeration of cell subsets from tissue expression profiles. Nat Methods (2015) 12:453-7. doi: 10.1038/nmeth.3337

23. Nirmal AJ, Regan T, Shih BB, Hume DA, Sims AH, Freeman TC. Immune cell gene signatures for profiling the microenvironment of solid tumors. Cancer Immunol Res (2018) 6:1388-400. doi: 10.1158/2326-6066.CIR-18-0342

24. Patir A, Shih B, McColl BW, Freeman TC. A core transcriptional signature of human microglia: Derivation and utility in describing region-dependent alterations associated with Alzheimer's disease. Glia (2019) 67:1240-53. doi: 10.1002/glia.23572

25. Szabo PA, Levitin HM, Miron M, Snyder ME, Senda T, Yuan J, et al. Single-cell transcriptomics of human $\mathrm{T}$ cells reveals tissue and activation signatures in health and disease. Nat Commun (2019) 10:4706. doi: 10.1038/s41467-019-12464-3

26. Bauer J, Bien CG, Lassmann H. Rasmussen's encephalitis: a role for autoimmune cytotoxic T lymphocytes. Curr Opin Neurol (2002) 15:197200. doi: 10.1097/00019052-200204000-00012

27. Pardo CA, Vining EP, Guo L, Skolasky RL, Carson BS, Freeman JM. The pathology of Rasmussen syndrome: stages of cortical involvement and neuropathological studies in 45 hemispherectomies. Epilepsia (2004) 45:516-26. doi: 10.1111/j.0013-9580.2004.33103.x

28. Farrell MA, Droogan O, Secor DL, Poukens V, Quinn B, Vinters HV. Chronic encephalitis associated with epilepsy: immunohistochemical and ultrastructural studies. Acta Neuropathol (1995) 89:313-21. doi: 10.1007/BF00309624

29. Corrie BD, Marthandan N, Zimonja B, Jaglale J, Zhou Y, Barr E, et al. iReceptor: A platform for querying and analyzing antibody/B-cell and T-cell receptor repertoire data across federated repositories. Immunol Rev (2018) 284:24-41. doi: 10.1111/imr.12666

30. Rosati E, Dowds CM, Liaskou E, Henriksen EKK, Karlsen TH, . Franke A. Overview of methodologies for T-cell receptor repertoire analysis. BMC Biotechnol (2017) 17:61. doi: 10.1186/s12896-017-0379-9

31. Dandekar S, Wijesuriya H, Geiger T, Hamm D, Mathern GW, Owens GC. Shared HLA Class I and II alleles and clonally restricted public and private brain-infiltrating alpha beta $\mathrm{T}$ cells in a cohort of Rasmussen encephalitis surgery patients. Front Immunol (2016) 7:608. doi: 10.3389/fimmu.2016.00608

32. Larsson S, Soderberg-Naucler C, Wang FZ, Moller E. Cytomegalovirus DNA can be detected in peripheral blood mononuclear cells from all seropositive and most seronegative healthy blood donors over time. Transfusion (1998) 38:271-8. doi: 10.1046/j.1537-2995.1998.38398222871.x

33. Serafini B, Rosicarelli B, Veroni C, Mazzola GA, Aloisi F. Epstein-Barr virusspecific CD8 T cells selectively infiltrate the brain in multiple sclerosis and interact locally with virus-infected cells: clue for a virus-driven immunopathological mechanism. J Virol (2019) 93:e00980-19. doi: 10.1128/JVI.00980-19

34. Walter GF, Renella RR. Epstein-Barr virus in brain and Rasmussen's encephalitis. Lancet (1989) 1:279-80. doi: 10.1016/S0140-6736(89)91292-0

35. Power C, Poland SD, Blume WT, Girvin JP, Rice GP. Cytomegalovirus and Rasmussen's encephalitis. Lancet (1990) 336:1282-4. doi: 10.1016/0140-6736 (90)92965-K

36. Vinters HV, Wang R, Wiley CA. Herpesviruses in chronic encephalitis associated with intractable childhood epilepsy. Hum Pathol (1993) 24:8719. doi: 10.1016/0046-8177(93)90137-6

37. Atkins MR, Terrell W, Hulette CM. Rasmussen's syndrome: a study of potential viral etiology. Clin Neuropathol (1995) 14:7-12.

38. Jay V, Becker LE, Otsubo H, Cortez M, Hwang P, Hoffman HJ, et al. Chronic encephalitis and epilepsy (Rasmussen's encephalitis): detection of cytomegalovirus and herpes simplex virus 1 by the polymerase chain reaction and in situ hybridization. Neurology (1995) 45:108-17. doi: 10.1212/WNL.45.1.108

39. McLachlan RS, Levin S, Blume WT. Treatment of Rasmussen's syndrome with ganciclovir. Neurology (1996) 47:925-8. doi: 10.1212/WNL.47.4.925

40. Dioverti MV, Razonable RR. Cytomegalovirus. Microbiol Spectr (2016) 4:1-26. doi: 10.1128/microbiolspec.DMIH2-0022-2015

41. Jenson HB. Epstein-Barr virus. Pediatr Rev (2011) 32:375-83. doi: 10.1542/ pir.32-9-375

42. Sinclair J. Human cytomegalovirus: Latency and reactivation in the myeloid lineage. J Clin Virol (2008) 41:180-5. doi: 10.1016/j.jcv.2007.11.014

43. Hatton OL, Harris-Arnold A, Schaffert S, Krams SM, Martinez OM. The interplay between Epstein-Barr virus and B lymphocytes: implications for infection, immunity, and disease. Immunol Res (2014) 58:268-76. doi: 10.1007/s12026-014-8496-1

44. Melzer N, Meuth SG, Wiendl H. CD8+ T cells and neuronal damage: direct and collateral mechanisms of cytotoxicity and impaired electrical excitability. FASEB J (2009) 23:3659-73. doi: 10.1096/fj.09-136200

45. Kreutzfeldt M, Bergthaler A, Fernandez M, Bruck W, Steinbach K, Vorm M, et al. Neuroprotective intervention by interferon-gamma blockade prevents CD8+ T cell-mediated dendrite and synapse loss. J Exp Med (2013) 210:2087103. doi: $10.1084 /$ jem. 20122143

46. Ehling P, Melzer N, Budde T, Meuth SG. CD8(+) T Cell-Mediated Neuronal Dysfunction and Degeneration in Limbic Encephalitis. Front Neurol (2015) 6:163. doi: $10.3389 /$ fneur.2015.00163

47. Di Liberto G, Pantelyushin S, Kreutzfeldt M, Page N, Musardo S, Coras R, et al. Neurons under $\mathrm{T}$ cell attack coordinate phagocyte-mediated synaptic stripping. Cell (2018) 175:458-71.e19. doi: 10.1016/j.cell.2018.07.049

48. Jung S, Gamez-Diaz L, Proietti M, Grimbacher B. "Immune TOR-opathies," a novel disease entity in clinical immunology. Front Immunol (2018) 9:966. doi: 10.3389/fimmu.2018.00966

49. Jones RG, Pearce EJ. MenTORing Immunity: mTOR signaling in the development and function of tissue-resident immune cells. Immunity (2017) 46:730-42. doi: 10.1016/j.immuni.2017.04.028

50. Zeng $\mathrm{H}$, Chi H. mTOR signaling in the differentiation and function of regulatory and effector T cells. Curr Opin Immunol (2017) 46:103-11. doi: 10.1016/j.coi.2017.04.005

51. Krueger DA, Wilfong AA, Mays M, Talley CM, Agricola K, Tudor C, et al. Long-term treatment of epilepsy with everolimus in tuberous sclerosis. Neurology (2016) 87:2408-15. doi: 10.1212/WNL.0000000000003400

52. Sotgiu S, Murrighile MR, Constantin G. Treatment of refractory epilepsy with natalizumab in a patient with multiple sclerosis. Case Rep BMC Neurol (2010) 10:84. doi: 10.1186/1471-2377-10-84

53. Bittner S, Simon OJ, Gobel K, Bien CG, Meuth SG, Wiendl H. Rasmussen encephalitis treated with natalizumab. Neurology (2013) 81:395-7. doi: 10.1212/WNL.0b013e31829c5ceb

54. Bien CG, Tiemeier H, Sassen R, Kuczaty S, Urbach H, von Lehe M, et al. Rasmussen encephalitis: incidence and course under randomized therapy with tacrolimus or intravenous immunoglobulins. Epilepsia (2013) 54:543-50. doi: 10.1111/epi.12042

55. Ayzenberg I, Hoepner R, Kleiter I. Fingolimod for multiple sclerosis and emerging indications: appropriate patient selection, safety precautions, and special considerations. Ther Clin Risk Manag (2016) 12:261-72. doi: 10.2147/ TCRM.S65558 
56. Lagarde S, Villeneuve N, Trebuchon A, Kaphan E, Lepine A, McGonigal A, et al. Anti-tumor necrosis factor alpha therapy (adalimumab) in Rasmussen's encephalitis: An open pilot study. Epilepsia (2016) 57:956-66. doi: 10.1111/ epi.13387

Conflict of Interest: The authors declare that the research was conducted in the absence of any commercial or financial relationships that could be construed as a potential conflict of interest.
Copyright (c) 2021 Chang, Reyes, Faure-Kumar, Lam, Lawlor, Leventer, Lew, Lockhart, Pope, Weiner, Salamon, Vinters, Mathern, Fallah and Owens. This is an open-access article distributed under the terms of the Creative Commons Attribution License (CC BY). The use, distribution or reproduction in other forums is permitted, provided the original author(s) and the copyright owner(s) are credited and that the original publication in this journal is cited, in accordance with accepted academic practice. No use, distribution or reproduction is permitted which does not comply with these terms. 


\section{University Library}

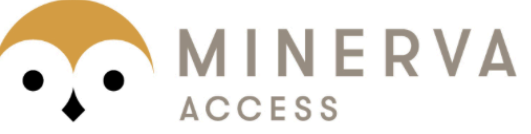

A gateway to Melbourne's research publications

Minerva Access is the Institutional Repository of The University of Melbourne

\section{Author/s:}

Chang, JW;Reyes, SD;Faure-Kumar, E;Lam, SK;Lawlor, MW;Leventer, RJ;Lew, SM;Lockhart, PJ;Pope, K;Weiner, HL;Salamon, N;Vinters, HV;Mathern, GW;Fallah, A;Owens, GC

Title:

Clonally Focused Public and Private T Cells in Resected Brain Tissue From Surgeries to Treat Children With Intractable Seizures

Date:

2021-04-06

\section{Citation:}

Chang, J. W., Reyes, S. D., Faure-Kumar, E., Lam, S. K., Lawlor, M. W., Leventer, R. J., Lew, S. M., Lockhart, P. J., Pope, K., Weiner, H. L., Salamon, N., Vinters, H. V., Mathern, G. W., Fallah, A. \& Owens, G. C. (2021). Clonally Focused Public and Private T Cells in Resected Brain Tissue From Surgeries to Treat Children With Intractable Seizures. FRONTIERS IN IMMUNOLOGY, 12, https://doi.org/10.3389/fimmu.2021.664344.

Persistent Link:

http://hdl.handle.net/11343/278073

License:

CC BY 